\title{
Comparison of GLUT1, GLUT2, GLUT4 and SGLT1 mRNA Expression in the Salivary Glands and Six Other Organs of Control, Streptozotocin-Induced and Goto-Kakizaki Diabetic Rats
}

\author{
Cedric Jurysta ${ }^{a}$ Charles Nicaise ${ }^{b}$ Marie-Hélène Giroix ${ }^{c}$ Sibel Cetik ${ }^{a}$ Willy J. Malaisse ${ }^{a}$ \\ Abdullah Senera \\ Laboratories of a Experimental Hormonology and ${ }^{b}$ General Histology, Neuroanatomy and \\ Neuropathology, Université Libre de Bruxelles, Brussels, Belgium; 'Equipe Biologie et Pathologie du \\ Pancréas Endocrine (B2PE), Unité BFA-CNRS EAC 4413, Université Paris-Diderot, Paris, France
}

\section{Key Words}

Salivary glands • Glucose transporters • GLUT1 • GLUT2 • GLUT4 • SGLT1 • Streptozotocininduced diabetes rats $\cdot$ GK rats

\begin{abstract}
Background/Aims: The expression and localization of several distinct glucose transporters (GLUT1, GLUT2, GLUT4, and SGLT1) was recently characterized in the parotid gland of normal rats by quantitative real-time PCR analysis, immunohistochemistry and Western blotting. The major aims of the present study was to compare the mRNA expression of these glucose transporters in both the parotid gland and submaxillary gland of control rats, streptozotocininduced diabetic rats and hereditarily diabetic Goto-Kakizaki rats. Methods: Quantitative realtime PCR analysis was performed in the parotid and submaxillary salivary glands and, for purpose of comparison, also in the heart, kidney, liver, lung, muscle and pancreas from control animals and either streptozotocin-treated or Goto-Kakizaki rats. Results: The expression of GLUT4, but not GLUT1 or SGLT1, mRNA was decreased in the diabetic rats. The results also allow comparing both the mRNA expression level of the four glucose transporters in salivary glands and six other organs, and the diabetes-induced changes in such an expression in distinct locations. Conclusion: The mRNA expression of the insulin-dependent GLUT4 transporter was the sole to be significantly decreased in the salivary glands of diabetic animals. The possible consequence of such a decrease in terms of the control of salivary glucose concentration requires further investigation.
\end{abstract}


Jurysta/Nicaise/Giroix et al.: Glucose Transporters in Salivary Glands

\section{Introduction}

It is generally admitted that the salivary glucose concentration is higher in diabetic patients than in control subjects [1]. Nevertheless, several factors may affect the relationship between blood and salivary glucose concentrations, such as the retention of alimentary carbohydrates [2,3] and hexose utilization by oral bacteria [4], to mention only two examples. The increase of salivary glucose concentration in the diabetic patients may participate to the alteration of periodontal health often prevailing in these patients $[5,6]$. In a recent study, we investigated the expression and localization of several distinct glucose transporters in acinar cells of rat parotid glands obtained from normal rats [7]. The major aim of the present investigations was to compare the mRNA expression of GLUT1, GLUT2, GLUT4 and SGLT1 in the parotid and submaxillary salivary glands, as well as in six other organs, in samples obtained from either control rats, streptozotocin-induced diabetic rats and hereditarily diabetic Goto-Kakizaki rats.

\section{Materials and Methods}

Four Wistar rats, four streptozotocin-induced diabetic rats (STZ rats) and four Goto-Kakizaki rats (GK rats), all of comparable age (about 11 weeks), had free access to food and water up to the time of euthanasia, exsanguination and decapitation [7]. Diabetic STZ rats were obtained as described elsewhere [8], GK rats were obtained from the Paris colony, initiated by the end of the 1980s [9] from the original Japanese colony [10] and maintained from that time at the University Paris-Diderot animal core [11]. Parotid and submaxillary glands, heart, kidney, liver, lung, soleus muscle and pancreas were removed and processed for quantitative real-time PCR analysis as previously described, according to the delta Ct method, the gene expression level of each mRNA being normalized to relative GAPDH (glyceraldehyde 3-phosphate dehydrogenase enzyme) mRNA [7]. Plasma glucose concentration in nonfasted state was measured using the method recommended by Bergmeyer and Bernt [12].

All animal experiments were conducted in accordance with accepted standards of animal care as established by the French National Centre for Scientific Research Guidelines and Brussels local ethic committee rules and the European Communities Council Directive (86/609/EEC).

All results are presented as mean values $( \pm$ SEM). The statistical significance of differences between mean values found in control versus either STZ or GK rats, as well as STZ versus GK rats, was assessed by the use of Student's $t$-test. As a rule, comparable information was obtained by ANOVA and Bonferroni's multiple comparison test.

\section{Results}

Body weight and plasma glucose

The body weight was significantly lower $(\mathrm{p}<0.005)$ in GK rats than in control animals, whilst the plasma glucose concentration was much higher $(\mathrm{p}<0.005)$ in STZ rats than in control animals (Table 1). The plasma glucose concentration was also somewhat higher $(\mathrm{p}<0.025)$ in $\mathrm{GK}$ rats than in control animals.

\section{Control rats}

In the control rats, the expression of GLUT1 mRNA was higher $(\mathrm{p}<0.001)$ in the salivary glands $\left(1,210 \pm 94.10^{-3} ; \mathrm{n}=8\right)$ than in lung $\left(470 \pm 33.10^{-3} ; \mathrm{n}=4\right)$, kidney $\left(158 \pm 2.10^{-3} ; \mathrm{n}=4\right)$ and pancreas $\left(97 \pm 40.10^{-3} ; n=4\right)$ with even lower values in heart $\left(40 \pm 6.10^{-3} ; n: 4\right)$, liver $(10$ $\left.\pm 1.10^{-3} ; \mathrm{n}=4\right)$ and muscle $\left(1.10^{-3} ; \mathrm{n}=4\right)$ (Table 2 ).

The expression of GLUT2 mRNA followed a liver > pancreas > kidney hierarchy, with much lower to negligible values in lung, muscle, heart and the two salivary glands (Table 3 ).

In the case of GLUT4, the highest values for mRNA expression were found in submaxillary gland $\left(74 \pm 210^{-3}\right)$, heart $\left(72 \pm 7.10^{-3}\right)$, muscle $\left(21.10^{-3}\right)$ and parotid gland $\left(13 \pm 3.10^{-3}\right)$, 


\begin{tabular}{lccc}
\hline Rats & Control & STZ & GK \\
\hline Body weight (g) & $402 \pm 13(4)$ & $365 \pm 30(4)$ & $275 \pm 24(4)$ \\
Plasma glucose $(\mathrm{mM})$ & $7.40 \pm 0.35(4)$ & $22.65 \pm 3.07(4)$ & $9.18 \pm 0.29(3)$ \\
\hline
\end{tabular}

Table 1. Body weight and plasma glucose concentration

\begin{tabular}{lccc}
\hline Rats & Control & STZ & GK \\
\hline Parotid $\left(10^{-3}\right)$ & $1,114 \pm 148(4)$ & $1,087 \pm 184(4)$ & $1,072 \pm 175(4)$ \\
Submaxillary $\left(10^{-3}\right)$ & $1,305 \pm 116(4)$ & $1,280 \pm 174(4)$ & $1,286 \pm 81(4)$ \\
Heart $\left(10^{-3}\right)$ & $39.7 \pm 6.0(4)$ & $18.2 \pm 4.7(4)^{\mathrm{b}}$ & $28.7 \pm 9.1(4)$ \\
Kidney $\left(10^{-3}\right)$ & $158.3 \pm 1.9(4)$ & $87.6 \pm 7.3(4)^{\mathrm{f}}$ & $117.9 \pm 9.6(4)^{\mathrm{d}}$ \\
Liver $\left(10^{-3}\right)$ & $10.4 \pm 0.9(4)$ & $24.7 \pm 1.4(4)^{\mathrm{f}}$ & $28.4 \pm 3.1(4)^{\mathrm{e}}$ \\
Lung $\left(10^{-3}\right)$ & $470 \pm 33(4)$ & $330 \pm 1(3)^{\mathrm{c}}$ & $301 \pm 14(3)^{\mathrm{d}}$ \\
Muscle $\left(10^{-3}\right)$ & $0.84 \pm 0.22(4)$ & $0.87 \pm 0.24(4)$ & $0.68 \pm 0.25(3)$ \\
Pancreas $\left(10^{-3}\right)$ & $97.3 \pm 40.1(4)$ & $15.5 \pm 5.4(4)^{\mathrm{a}}$ & $56.0 \pm 13.4(4)$ \\
\hline
\end{tabular}

Table 2. GLUT1 mRNA expression. a: $\mathrm{p}<0.1$; $\mathrm{b}$ p $<0.05$; : $\mathrm{p}<0.02$; : $\mathrm{p}<0.01$; : $\mathrm{p}<0.005$; : $\mathrm{p}<0.001$ versus control

\begin{tabular}{lccc}
\hline Rats & Control & STZ & GK \\
\hline Parotid $\left(10^{-4}\right)$ & $1.2 \pm 0.1(4)$ & $5.1 \pm 2.8(3)$ & $3.3 \pm 0.9(4)^{\mathrm{a}}$ \\
Submaxillary $\left(10^{-4}\right)$ & $0.37 \pm 0.03(4)$ & $0.41 \pm 0.01(4)$ & $0.31 \pm 0.05(4)$ \\
Heart $\left(10^{-4}\right)$ & $0.02 \pm 0.00(4)$ & $0.04 \pm 0.02(4)$ & $0.03 \pm 0.01(4)$ \\
Kidney $\left(10^{-4}\right)$ & $1,000 \pm 216(4)$ & $1,100 \pm 49(4)$ & $1,460 \pm 145(4)$ \\
Liver $\left(10^{-4}\right)$ & $5,483 \pm 1,228(4)$ & $9,035 \pm 292(4)^{\mathrm{b}}$ & $9,108 \pm 156(4)^{\mathrm{b}}$ \\
Lung $\left(10^{-4}\right.$ & $2.8 \pm 0.7(4)$ & $13.7 \pm 3.0(3)^{\mathrm{d}}$ & $13.3 \pm 4.1(3)^{\mathrm{b}}$ \\
Muscle $\left(10^{-4}\right)$ & $0.06 \pm 0.02(4)$ & $0.00 \pm 0.00(4)^{\mathrm{a}}$ & $0.02 \pm 0.01(4)$ \\
Pancreas $\left(10^{-4}\right)$ & $2,538 \pm 758(4)$ & $409 \pm 53(3)^{\mathrm{a}}$ & $521 \pm 74(4)^{\mathrm{b}}$ \\
\hline
\end{tabular}

Table 3. GLUT2 mRNA expression. a: $p<0.1$; : $p<0.05$; : $p<0.02$; : $p<0.01$; : $p<0.005$; : $p<0.001$ versus control

\begin{tabular}{lccc}
\hline Rats & Control & STZ & GK \\
\hline Parotid $\left(10^{-4}\right)$ & $129 \pm 33(4)$ & $41 \pm 10(4)^{\mathrm{b}}$ & $44 \pm 4(4)^{\mathrm{b}}$ \\
Submaxillary $\left(10^{-4}\right)$ & $744 \pm 21(4)$ & $615 \pm 27(4)^{\mathrm{d}}$ & $527 \pm 49(4)^{\mathrm{d}}$ \\
Heart $\left(10^{-4}\right)$ & $720 \pm 69(4)$ & $350 \pm 11(4)^{\mathrm{e}}$ & $351 \pm 37(4)^{\mathrm{e}}$ \\
Kidney $\left(10^{-4}\right)$ & $39.1 \pm 1.3(4)$ & $22.3 \pm 0.6(4)^{\mathrm{f}}$ & $19.0 \pm 4.2(4)^{\mathrm{e}}$ \\
Liver $\left(10^{-4}\right)$ & $0.42 \pm 0.09(4)$ & $0.52 \pm 0.07(4)$ & $0.55 \pm 0.05(4)$ \\
Lung $\left(10^{-4}\right)$ & $38.4 \pm 1.6(4)$ & $17.2 \pm 3.0(4)^{\mathrm{f}}$ & $36.2 \pm 9.5(4)$ \\
Muscle $\left(10^{-4}\right)$ & $209 \pm 2(4)$ & $207 \pm 16(4)$ & $295 \pm 72(4)$ \\
Pancreas $\left(10^{-4}\right)$ & $36 \pm 4(4)$ & $64 \pm 10(4)^{\mathrm{b}}$ & $61 \pm 16(4)$ \\
\hline
\end{tabular}

Table 4. GLUT4 mRNA expression. a: $p<0.1$; : $p<0.05$; : $p<0.02$; : p < 0.01; e: $p<0.005$; $:$ p $<0.001$ versus control

followed by pancreas $\left(4.10^{-3}\right)$, kidney $\left(4.10^{-3}\right)$, lung $\left(4.10^{-3}\right)$ and liver (no more than $0.04 .10^{-3}$ ) (Table 4).

Last, the expression of SGLT1 mRNA again yielded the highest mean value in salivary glands $\left(1,313 \pm 170.10^{-4} ; n=8\right)$ and lung $\left(1,023 \pm 24.10^{-4} ; n=4\right)$, followed by kidney $\left(554 \pm 34.10^{-4} ; \mathrm{n}=4\right)$, pancreas $\left(196 \pm 18.10^{-4} ; \mathrm{n}=4\right)$, liver $\left(22 \pm 3.10^{-4} ; \mathrm{n}=4\right)$, heart $(0.2 \pm$ $\left.0.1 .10^{-4} ; \mathrm{n}=4\right)$ and muscle $\left(0.04 \pm 0.01 .10^{-4} ; \mathrm{n}=4\right)$. Such a hierarchy was similar to that found for GLUT1.

The data listed in Tables 2 to 5 also document that, in salivary glands, the expression of distinct transporter genes yielded, in the control rats, the following hierarchy: GLUT 


\begin{tabular}{lccc}
\hline Rats & Control & STZ & GK \\
\hline Parotid $\left(10^{-4}\right)$ & $1,337 \pm 361(4)$ & $710 \pm 71(4)$ & $688 \pm 85(4)$ \\
Submaxillary $\left(10^{-4}\right)$ & $1,298 \pm 72(4)$ & $1,472 \pm 243(4)$ & $1,408 \pm 239(4)$ \\
Heart $\left(10^{-4}\right)$ & $0.16 \pm 0.06(4)$ & $0.24 \pm 0.04(4)$ & $0.35 \pm 0.04(4))^{\mathrm{b}}$ \\
Kidney $\left(10^{-4}\right)$ & $554 \pm 34(4)$ & $230 \pm 21(4)^{\mathrm{f}}$ & $228 \pm 18(4)^{\mathrm{f}}$ \\
Liver $\left(10^{-4}\right)$ & $22.0 \pm 2.9(4)$ & $24.6 \pm 3.5(4)$ & $35.2 \pm 5.7(4)^{\mathrm{a}}$ \\
Lung $\left(10^{-4}\right)$ & $1,023 \pm 24(4)$ & $937 \pm 172(4)$ & $1,370 \pm 125(4)$ \\
Muscle $\left(10^{-4}\right)$ & $0.04 \pm 0.01(4)$ & $0.01 \pm 0.01(4)^{\mathrm{a}}$ & $0.04 \pm 0.01(4)$ \\
Pancreas $\left(10^{-4}\right)$ & $196 \pm 18(4)$ & $114 \pm 18(4)^{\mathrm{c}}$ & $500 \pm 133(4)^{\mathrm{a}}$ \\
\hline
\end{tabular}

Table 5. SGLT1 mRNA expression. a: $p<0.1$; : $p<0.05$; c: $p<0.02$; : $p<0.01$; e: $p<0.005$; : $p<0.001$ versus control

$1>$ SGLT1 > GLUT4 > GLUT2 with a difference of about one order of magnitude or more between successive transporters listed in such a hierarchy. A different situation prevailed in liver and pancreas with the following hierarchy: GLUT2>GLUT1>SGLT1>GLUT4. In kidney, the mRNA expression was highest for GLUT1 and lowest for GLUT4 with in-between values for GLUT2 and SLGT1. Last, in muscle, the mRNA expression of GLUT4 largely exceeded that of GLUT1, with negligible values for both GLUT2 and SGLT1.

\section{STZ rats}

No significant difference in GLUT1 data was found in either the parotid or submaxillary gland when comparing STZ rats to control animals (Table 2). In most other organs, i.e. in heart, kidney, lung and pancreas, the mean values for GLUT1 were lower in STZ rats than in control animals. Thus, in the former STZ rats, the recorded values averaged $45.3 \pm 6.2 \%$ $(\mathrm{n}=15 ; \mathrm{p}<0.001)$ of the mean corresponding values found in control animals $(100.0 \pm$ $9.9 \% ; \mathrm{n}=16$ ). In this respect, the two sole exceptions were observed in liver, in which the GLUT1 measurements were twice higher in STZ rats than in control animals $(\mathrm{p}<0.001)$, and in muscle, in which GLUT1 measurements were at least one order of magnitude lower than in other organs.

Two individual values for GLUT2 found respectively in the pancreas and parotid gland of the same STZ rat exceeded the upper limit of the 95\% individual confidence interval as derived from the recordings recorded in the 3 other STZ rats and, hence, were discarded when computing the mean values listed in Table 3. Even when the GLUT2 value found in the parotid gland of this STZ rat $\left(257.10^{-5}\right)$ was taken into account, no significant difference was reached between the control animals and STZ rats. Incidentally, when taking all individual values into account, a significant positive correlation $(r=+0.95 ; p=0.05)$ was found in the 4 STZ rats between the individual data collected for the expression of GLUT2 in the pancreas, on one hand, and the parotid gland, on the other hand ( $\mathrm{n}=4$ in both cases). No significant difference between control and STZ rats was observed in the case of GLUT2 in the parotid and submaxillary glands, kidney, heart and muscle. In other organs, the salient findings consisted in an apparent decrease of GLUT2 in the pancreas of STZ rats ( $<0.07)$ and an apparent increase in GLUT2 in liver and lung ( $\mathrm{p}<0.05$ or less).

In the STZ rats, the expression of GLUT4 mRNA was decreased in the parotid and submaxillary glands, heart, kidney and lung, in which organs it averaged $52.9 \pm 4.4 \%$ $(\mathrm{n}=20 ; \mathrm{p}<0.001)$ of the corresponding mean values recorded in the control animals $(100.0$ $\pm 5.0 \% ; \mathrm{n}=20$ ).

It was not significantly different in STZ rats and control animals, whether in liver or muscle, but appeared increased in the pancreas of the STZ rats (Table 4).

Last, as far as SGLT1 is concerned, a significant decrease in mRNA expression was observed in the kidney and pancreas. Such was not the case in other organs. For instance, in the salivary glands, the expression of SGLT1 mRNA averaged 1,313 $\pm 170.10^{-4}(\mathrm{n}=8)$ in control animals, as compared ( $p>0.3)$ to $1,091 \pm 186.10^{-4}(n=8)$ in STZ rats. 


\section{GK rats}

In one GK rats, the GLUT1 value in muscle $\left(596.10^{-5}\right)$ and GLUT2 value in lung $\left(682.10^{-5}\right)$ largely exceeded the upper limit of the $95 \%$ individual confidence interval for the readings recorded in the other $3 \mathrm{GK}$ rats and, hence, were discarded from the further analysis of data.

The other results recorded in the GK rats were often comparable to those found in STZ rats. As a matter of fact, only the following significant differences were found between these two groups of rats.

First, in the case of GLUT1, the values found in kidney and pancreas were higher ( $\mathrm{p}<$ 0.005 ) in GK rats than in STZ rats. Thus, in these two organs, as well as in heart, the mean values for GLUT1 yielded a control > GK > STZ hierarchy.

Second in the case of GLUT2, no significant difference was found between STZ and GK rats in any of the 8 locations under consideration. It should be stressed, however, that the mean values found in these diabetic rats were higher than those recorded in control rats in the parotid gland, liver and lung where they averaged $314 \pm 48 \%(\mathrm{n}=21 ; \mathrm{p}<0.005)$ of the mean corresponding control values $(100 \pm 10 \%$; $n=12)$, whilst a mirror image prevailed in the pancreas, in which case the values found in the diabetic STZ and GK rats represented no more than $19 \pm 2 \%(n=7 ; p<0.005)$ of the mean corresponding control values $(100 \pm 30 \%$; $\mathrm{n}=4)$.

Third, in the case of GLUT4, once again no significant difference was found between STZ and GK rats in any of the 8 locations under consideration. The salient findings were the lower values found in the parotid and submaxillary glands, heart and kidney of diabetic rats, as compared to control animals, and the higher mean values found in the pancreas of diabetic rats, as distinct from control animals.

Last, in the case of SGLT1, the sole statistically significant difference $(\mathrm{p}<0.05)$ between STZ and GK rats concerned the pancreatic gland. Even so, however, the overall value found in the pancreas of diabetic rats did not differ significantly $(p>0.4)$ from that recorded in the control animals. The sole salient finding consisted in the lower SGLT1 values recorded in the parotid gland and kidney of diabetic rats, as compared to control animals, the former values averaging $47.0 \pm 2.6 \%(\mathrm{n}=16 ; \mathrm{p}<0.001)$ of the corresponding mean control values $(100.0$ $\pm 12.9 \% ; \mathrm{n}=8$ ).

\section{Discussion}

The present study affords three major new pieces of information.

First, it extends the comparison in control rats between the level of mRNA expression for the four glucose transporters under consideration in salivary glands and six other locations. In such a respect, the present data are in close agreement with recent findings restricted to the comparison between the parotid gland and one selected positive and one selected negative control [7]. The results indicate that GLUT1 mRNA expression is one order of magnitude higher in salivary glands than in kidney or pancreas. Likewise, SGLT1 mRNA expression is also much higher in the salivary glands than in kidney or pancreas. In the salivary glands, GLUT2 mRNA expression is negligible in sharp contrast to the situation found in liver or pancreas. Last, GLUT4 mRNA expression is higher in the submaxillary gland, heart and muscle than in the parotid gland.

Second, the present results allow comparing the level of mRNA expression of distinct glucose transporters in the same tissue. For instance, the measurements recorded in salivary glands document a GLUT 1 > SGLT1 > GLUT4 > GLUT2 hierarchy, with a close-to-one order of magnitude difference or more between two successive transporters listed in this hierarchy.

Third, the present study reveals that GLUT4 mRNA expression was significantly decreased in the salivary glands of diabetic rats, as compared to control animals. Such was also the case for this insulin-dependent transporter in heart and kidney, as well as in lung at least in the STZ rats. 
Jurysta/Nicaise/Giroix et al.: Glucose Transporters in Salivary Glands

Another diabetes-induced change in mRNA expression in the salivary glands merit to be underlined. In the parotid gland, but not so in submaxillary gland, the mean mRNA level of SGLT1 was lower $(\mathrm{p}<0.05)$ in the diabetic rats $\left(699 \pm 51.10^{-4} ; \mathrm{n}=8\right)$ than in the control rats $\left(1,327 \pm 361.10^{-4} ; n=4\right)$, at variance with a recent observation [13]. It should be stressed, however, that, in the latter observation, the sex of the diabetic rats (male rats), the diabetogenic agent (alloxan) and the reference gene ( $\beta$-actin) differed from those used in the present study. Moreover, in the recent investigation reported by Sabino-Silva et al. [13], the increase of SGLT1 mRNA in the parotid and submandibular glands observed in the diabetic rats contrasted with a lower corresponding protein content of SGLT1 in the same salivary glands of the same diabetic animals. Inversely, the mean GLUT2 mRNA was higher in the parotid gland of diabetic rats $\left(41 \pm 12.10^{-5} ; \mathrm{n}=7\right)$ than in the parotid gland of control animals $\left(12 \pm 1.10^{-5} ; \mathrm{n}=4\right)$, but such a difference did not achieve statistical significance $(p>0.5)$. Such remained the case $(p>0.2)$ even after inclusion of an abnormally high value $\left(217.10^{-5}\right)$ recorded in one STZ rat.

As a rule, the results recorded in the present study in other organs than salivary glands, were in fair agreement with current knowledge, whenever available. For instance, the high level of GLUT2 mRNA expression in liver and presumably endocrine pancreas of control rats and the opposite effects of diabetes to increase GLUT2 mRNA expression in liver and to decrease GLUT2 mRNA expression in presumably endocrine pancreas are indeed consistent with current knowledge [14].

Although the diabetes-induced decrease of GLUT4 mRNA expression in salivary glands should not be ignored, the present results suggest that an alteration of glucose transporters expression in salivary glands may only represent a limited determinant of the increase in salivary glucose concentration usually prevailing in diabetic patients [1]. Nevertheless, further functional investigations are obviously desirable to assess whether changes in selected aspects of glucose transport may possibly coincide with the present findings.

\section{Acknowledgements}

This work was supported by grant 3.4520 .07 (to A.S.) from the Belgian Foundation for Scientific Medical Research. The secretarial help of C. Demesmaeker is gratefully acknowledged.

\section{References}

1 Jurysta C, Bulur N, Oguzhan B, Satman I, Yilmaz TM, Malaisse WJ, Sener A: Salivary glucose concentration and excretion in normal and diabetic subjects. J Biomed Biotechnol 2009;2009:430-436.

- Hase JC, Birkhed D: Oral sugar clearance in elderly people with prosthodontic reconstructions. Scan J Dent Res 1991;91:333-339.

-3 Hase JC, Birkhed D, Lagerlöf F, Thornqvist E: Oral retention of glucose at pharmacologically reduced salivary flow in man. Scand J Dent Res 1994;102:180-185.

-4 de Jong MH, van der Hoeven JS, van Os JH, Olijve JH: Growth or oral Streptococcus species and Actinomyces viscosus in human saliva. Appl Environ Microb 1984;47:901-904.

5 Jurysta C, Cetik S, Boz M, Bulur N, Mahvelati G, Malaisse WJ, Vanden Abbeele A, Sener A: Comparison of DMFT indexes between diabetic and non-diabetic patients. Metab Funct Res Diab 2010;3:25-29.

6 Mahvelati G, Jurysta C, Boz M, Bulur N, Malaisse WJ: Comparison of PI and DPSI indices in diabetic and normal subjects. Metab Funct Res Diab 2012;5:11-16.

7 Jurysta C, Nicaise C, Cetik S, Louchami K, Malaisse WJ, Sener A: Glucose transport by acinar cells in rat parotid glands. Cell Physiol Biochem 2012;29:325-330.

8 Belkacemi L, Selselet-Attou G, Hupkens E, Nguidjoe E, Louchami K, Sener A, Malaisse WJ: Intermittent Fasting Modulation of the Diabetic Syndrome in Streptozotocin-Injected Rats. Inter J Endoc 2012;2012:112. 
9 Portha B, Serradas P, Bailbé D, Suzuki K-I, Goto Y, Giroix M-H: $\beta$-cell insensitivity to glucose in the GK rat, a spontaneous nonobese model for type II diabetes. Diabetes 1991;40:486-491.

10 Goto Y, Kakizaki M, Masaki N: Spontaneous diabetes produced by selective breeding of normal Wistar rats. Proc Jpn Acad 1975;51:80-85.

11 Portha B, Giroix M-H, Tourrel-Cuzin C, Le-Stunff H, Movassat J: The GK rat: a prototype for the study of nonoverweight type 2 diabetes. Methods Mol Biol 2012;933:125-159.

12 Bergmeyer HU, Bernt E: Glucose determination with glucose oxidase and peroxidase; in Bergmeyer HU (ed): Methods of Enzymatic Analysis. Academic Press, 1974, pp 1205-1215.

-13 Sabino-Silva R, Freitas HS, Lamers ML, Okamoto MM, Santos MF, Machado UF: $\mathrm{Na}^{+}$-glucose cotransporter SGLT1 protein in salivary glands: potential involvement in the diabetes-induced decrease in salivary flow. J Membrane Biol 2009;228:63-69

14 Leturque A, Brot-Laroche E, Le Gall M: GLUT2 mutation, translocation, and receptor function in diet sugar managing. Am J Physiol Endocrinol Metab 2009;296:E985-E992. 